\title{
The Conflict between the Pursuit of Integrity and Performance in Public Procurement
}

\author{
Bagassé Hervé Kafimbou, ${ }^{1,2}$ \\ ${ }^{1}$ Public Procurement Regulatory Authority, Ouagadougou, Burkina Faso \\ ${ }^{2}$ Laboratory of Economic Analysis and Policy, University Ouaga 2, Ouagadougou, Burkina Faso \\ Email: kafimbou@gmail.com
}

How to cite this paper: Kafimbou, B.H. (2019) The Conflict between the Pursuit of Integrity and Performance in Public Procurement. Theoretical Economics Letters, 9, 1294-1298.

https://doi.org/10.4236/tel.2019.95083

Received: March 15, 2019

Accepted: May 24, 2019

Published: May 27, 2019

Copyright (อ 2019 by author(s) and Scientific Research Publishing Inc. This work is licensed under the Creative Commons Attribution International License (CC BY 4.0).

http://creativecommons.org/licenses/by/4.0/

Open Access

\begin{abstract}
Does a reduction in the discretion of the public buyer through strict regulatory and procedural control make it possible to reduce corruption and increase the efficiency of public procurement? Using a multitasking agency model, we analyze the interactions between integrity concerns and the performance objective in public procurement. We show that the effect of coercive measures on the behavior of the procurer is counterintuitive. The model explains that the extrinsic formal incentives (control, sanction) are likely to produce effects far from those sought not only by reducing the effort to the performance of the buyer but especially by not acting against the corruption. These findings challenge some beliefs about the effectiveness of rigid rules and procedures in fighting corruption and improving public procurement performance.
\end{abstract}

\section{Keywords}

Public Procurement, Corruption, Discretion, Model of Agency

\section{Introduction}

Public procurement is the process by which a public authority acquires (from economic operators) goods, services and works required for the realization of public service missions. The question of their control has always been central to public policy. This interest is explained, on the one hand, by the growing role of public procurement in the development of the economy and, on the other hand, by the managerial practice judged to be corruptive and fraudulent in public procurement [1]. Indeed, the issue of government procurement raises serious governance issues: bureaucracy, corruption, fraud and inefficiency [2]. The size of the sums involved at least $15 \%$ of gross domestic product and $50 \%$ of public 
expenditure [3] [4] [5], and the constant interaction between public and private sectors exacerbate these problems.

Faced with these economic stakes and the potential incentive in terms of corruption, the reaction was to frame the public procurement by a body of rigid procedural rules [6]. The public purchase is thus organized, in detail, at each of its stages (decision to award a contract, choice of procedure, selection of the holder, execution of the contract, etc.) and accompanied by sanctions. The rules governing public contracts are supplemented by those governing the activity of public authorities and their agents ${ }^{1}$. This regulatory rigor supported by the World Bank makes corruption, especially that of civil servants, the core problem of public procurement [7] [8]. The IMF's 2005 report states that corruption in government procurement is the most severe type of corruption [9]. Therefore, to improve the efficiency of public procurement, the order given is to reduce, or even eliminate, corruption by increasing the control and monitoring and reducing the discretion of a purchasing agent.

But, is the regulatory and procedural rigor that considerably limits the discretion of the public purchaser ultimately more efficient for the public procurement? In view of the criticism made by the practitioners and through the analysis of the academic literature, one can doubt it. Indeed, the massive body of rules and oversight structures is deemed ineffective by practitioners and academics to curb corruption [10] [11] [12] [13]. It would, however, be a source of demotivation of civil servants and undermine the performance of public procurement. The conviction nurtured and maintained by the World Bank and international bodies fighting corruption, according to which the problem of public procurement would be the corruption of officials is put back into debate by [14] and [15]. In particular, these authors criticize the World Bank for not discriminating between inefficiency and incompetence on the one hand and corruption on the other hand in the failing management of public procurement.

This article is strongly inspired by these controversies. Two complementary theoretical arguments seem to provide an explanation for this situation. First, regulatory rigidity is intended to ensure transparency and to prevent manipulation of the public procurement process by public officials. It is often argued that improving the transparency of the decision-making process is a cure for corruption [16]. [17] argue that strict procedural rules can be used to align the interests of the principal and the agent, thereby limiting favoritism and corruption. Then, since the beginning of the 90 's, the New Public Management calls for a reduction of the control exerted on the public purchasers. For this stream, the procurement process should be based on the discretion and empowerment of public purchasers to achieve the goals set by the principal. It argues that the heaviness and stiffness of regulatory control limit the scope of public officials who react by adapting risk strategies. This risk leads buyers to focus on compliance with the formal rules, which is a means to the detriment of the pursuit of economic effi${ }^{1}$ General principles (e.g. legality, notion of general interest), statutory provisions, rules of conduct (e.g. disinterestedness, probity, discretion.), anti-corruption law and law against illicit enrichment. 
ciency, which is a result.

At the first argument is added the pressure increasingly pushed to an instrumental use of procurement [18] [19] [20] [21]. Indeed, because of the economic weight of the public procurement, it is tempting to use it to fulfill objectives foreign to public procurement. An instrumental use that brings additional stress to the public purchaser forced to arbitrate between the buying public purpose and socio-economic objectives and/or policies. Because of multiplicity of objectives, the effectiveness in achieving a given objective depends on the allocation of effort between the different objectives [22] [23].

By combining the two preceding arguments, two different rationales will underlie the activity of the public purchaser: the legal rationality that carries the imperative of strict compliance and the managerial rationality that brings with it an imperative of economic efficiency. However, the literature has not sufficiently taken into account how government integrity concerns can affect purchasing agent performance and the effectiveness of government procurement. Following Segal's [24] reflection, having to choose between efficiency and the integrity of public procurement is neither desirable nor tenable. Without efficiency, the public procurement process is unsatisfactory. Without integrity, it loses its legitimacy and cannot last because it is not in the service of the citizen.

This article aims to fill this gap by analyzing how control systems influence corruption and performance in public procurement. It is particularly interested in the answer to be given to the question "what is the influence of regulatory and procedural rigidity on corruption and performance in government procurement?". The interest is to evaluate the effectiveness of instruments traditionally used (monitoring, control, sanction) against corruption and for the promotion of performance in public procurement. To do this, a theoretical model is proposed in line with the principal-agent framework with multitasking developed by [23]. This model provides tools to analyze the relationships between corruption and performance tasks in public procurement and to predict the agent's effort allocation. To contribute to filling the gap of theoretical literature, the paper explicitly takes into account the existence of conflicting objectives that impose arbitration and different efforts to the public buyer. It redefines and incorporates in the model the structure of the sanctions against the public buyer contrary to the previous literature.

The rest of the article is organized as follows. The next section presents an arbitration model between integrity and performance in public purchase. The proposals of the model are discussed. Section 3 analyzes the limitations of the theoretical formulations. The fourth section concludes.

\section{The Formulation of Model}

There are different hierarchical levels in the public administration, each with a certain level of discretion. Generally, three levels exist: the administrative elite, managers and supervisors, and agents without accountability. They are all part 
of the bureaucratic chain but are not exposed to corruption in the same way. As a result, the control, oversight and sanctions applied to those are differentiated. In any public procurement, these three hierarchical levels are found at different levels of intervention. The administrative elite is at a political decision level and authorizes spending (budget authorizing officer). Administrative officers (managers and supervisors) are responsible for coordinating and monitoring the implementation of the authorizing officer's decisions. This corresponds to a technical translation of political decisions. Third level officers are responsible for operational implementation and are in fact the first point of contact with public service users.

The procurement can be considered as an agency relationship in which the contracting authority (the principal) delegates to a civil servant (the agent) the charge of the operational implementation of the procurement procedures [24] $[25]^{2}$. Specifically Klitgaard [24] uses a principal-agent-client framework to explain the phenomenon of corruption where the principal (a policy maker) authorizes his/her agent (an official) to provide services to clients (recipients of services). In the context of government procurement, the principal delegates his decision-making and purchasing power to the agent. These decisions, because of the divergence of objectives that may exist between principal and agent, may not be in the advantage of the principal.

Under this model, the contracting authority (the principal) has two objectives: curbing corruption and improving public procurement efficiency [26]. It is assumed that the agent also pursues two objectives: corruption effort for personal enrichment and public procurement performance effort for public service interest.

It is assumed that strictly compliant purchasing behavior can prevent corruption. In addition, it is assumed that a non-compliance purchase, i.e any deviation from the rules and procedures, reflects a corrupt attitude on the part of the procurement officer.

\subsection{The Model}

The model is based on the theoretical framework of principal-agent models with multitasking pioneered by [23]. By developing their model, Holmstrom and Milgrom [23] discuss problems related to the substitutability of multiple tasks. A multitasking situation is a configuration in which the agent has either multiple tasks or a multi-dimensional task. Intuitively, if the principal wants the agent to conduct these assigned tasks, he or she must ensure that the incentive mechanism balances the incentives for these activities. Holmstrom and Milgrom, [23] indicate that incentives direct the allocation of effort between tasks, in addition to assigning risk and inducing effort.

By this theoretical framework, [23] have uncovered a new source of conflict of interest in principal-agent relationships that may emerge when the agent is expected to perform multiple tasks at the same time. They pointed out that the fi${ }^{2}$ Susan Rose-Ackerman [25] and Robert Klitgaard [24] are considered the first authors to have established the link between corruption and the principal-agent model. 
nal distribution of efforts depends on the one hand on the relations between the tasks in the utility function of the agent and on the other hand on the system of devices that the principal establishes to assign the tasks in question (job design) and to evaluate (evaluation system) and incentive (incentive system) their performance. This basic model will provide us with the tools to analyze the relationships between the objectives and the efforts that they require in the case of public procurement and to predict on the basis of this analysis the behavior patterns of the principal and the agent.

Kwon [27] developed a similar model based on [23]. He was interested in public service in general. As a result, his model is a general framework for the public service. In doing so, the specificity of the public procurement is not taken into account. Also in his model, Kwon [27] uses the market wage as a penalty, assuming that the dismissal of the corrupt agent allows him to return immediately to employment in the private sector. This assumption is far from realistic because, apart from the loss of employment and the direct income attached to it, there are indirect losses. In addition, the model we propose differs from that of Kwon [27] by the basis of the sanction. We consider that the penalty only relates to the deviation from the norm while [27] assumes that all control is followed by a global penalty. This assumption is contrary to the current practice in the public service in general and in the area of public procurement in particular.

In the model developed below, the public official is supposed to pursue a set of tasks, which Simon [28] calls "types of possible behavior", which identifies itself with the qualification of the agent in question. Each particular behavior symbolizes "a set of tasks executed with the same level of detail, intensity". The two tasks pursued by the agent in the management of the procurement process are the corrupt transaction for his private benefit and the performance of the public procurement for the benefit of the public service. The private benefit derived from corruption is a function of the effort spent to achieve corruption. Formally $B=b e_{c}$.

In line with the pessimistic view of regulatory power vis-à-vis the public official [29], that the agent is supposed to derive personal benefit by not strictly adhering to the rules and procedures. In other words, it is assumed that the agent necessarily withdraws a personal monetary benefit by deviating from compliance rules. This leads us to accept the hypothesis of risk aversion for agent and risk neutrality for the principal. It is further assumed that procurement efficiency is a function of the level of performance effort spent. Hence the notation $P=p e_{p}+\varepsilon$, where $\varepsilon$ represents the standard error term of mean zero, $b$ and $p$ are respectively the marginal productivity of the corrupt effort and the marginal productivity of the effort to the performance of the public service.

The efforts of the agent are not known but their consequences are measured by the conduct of the purchasing process. The principal cannot observe the corruption effort $e_{c}$ nor the performance effort $e_{p}$, nor the bribery $B$, because corruption being by definition an occult transaction. This creates an information asymmetry between the agent and the principal. However, it is assumed that the 
performance effort for procurement $P$ can be observable and verifiable thanks to the level of performance achieved.

In addition, it is possible to detect a case of non-compliance by means of audits with a probability $q$. If such a case is revealed, the agent is sanctioned. It is assumed that because of complexity of the legal framework, the agent is always required to take a non-compliant act in the context of the awarding of contracts. Which induces a level of optimal non-compliance always positive $e_{c}^{*} \cdot q$ is the probability of agent being audited, and we assume that $e_{c}^{*}$ is always positive, suggesting that at each audit the agent will be sanctioned. Which is tantamount to saying that the probability of sanction is equal to $q$.

To remain in the logic of the public service, it will be supposed that the sanction causes a loss of income in all generality. This simplification does not obscure the fact that in public administration, in particular public procurement, behavior that is considered deviant or non-compliant may give rise to different types of single or cumulative isolated sanctions depending on the degree of seriousness of the offense deviant act. This may include the prohibition of the agent from participating in any procurement activity, criminal and/or financial penalty or dismissal from the public administration. In all cases, the penalty of any kind (increase of function, dismissal, pecuniary/penal sanction) induces a direct or indirect loss of income. Consequently, it is logical to assume that the penalty $F$ is a function of income and fault $F=q(1-\rho) W$ where $\rho \in[0,1]$ is compliance level reached or achieved and reflects the fact that the penalty covers only the deviation from the norm.

The utility function of the agent can then be summarized as follows:

$$
U=(1-q)(W+B)+q(1-\rho) W-C\left(e_{c}, e_{p}\right)
$$

$W$ is the salary received as a civil servant responsible for procurement contracts. We assumed $q$ to be the probability of the agent being caught for non-compliant and sanctioned behavior. As a result, he has a chance $1-q$ that his behavior is not detected because unaudited. In this case, the total gain of the agent is the sum of his salary and the product of his deviant behavior $(W+B)$.

The use of effort and time by the agent produces a disutility expressed by the personal cost function ${ }^{3}$. We consider a quadratic personal cost function. Examples of authors using quadratic cost functions include Rob et Zemsky [30], Socorro [31] et Martimort et Pouyet [32]. It is assumed that the cost function is strictly increasing and convex in his arguments $\left(C^{\prime}>0, C^{\prime \prime}>0\right.$ and $C(0,0)=0)$. Hence the cost function is: $C\left(e_{c}, e_{p}\right)=\frac{1}{2} e_{p}^{2}+\frac{1}{2} e_{c}^{2}+\gamma e_{p} e_{c}$, where $\gamma \in] 0,1\left[=\frac{\partial^{2} C\left(e_{c}, e_{p}\right)}{\partial e_{c} e_{p}}\right.$ ensures that tasks of corruption and performance are

${ }^{3}$ The concept of personal cost may be broader than the agent's only "expenditure" of time and effort (which has its alternative value in other activities in which he can invest). It also includes the emotional, psychological and mental costs associated with a tension between the nature/structure of the task the agent is expected to perform and his/her personal preferences or, in other words, his or her intrinsic motivations for carrying out a particular task. 
mutually substitutable relative to the agent personal cost.

Increasing effort for one activity increases the marginal cost of doing the other. The fact that the increased effort for a task increases the personal cost more than one might expect in the case of a single activity adversely affects the productivity of the agent.

Compensation $W$ perceived by the agent is composed of a basic salary $K$, constant, which is the categorical salary and an allowance depending on his performance attitude to the purchase $\beta P . \beta$ can be interpreted as the strength of the motivation of the agent. As a result one can write the remuneration $W$ as following: $W=K+\delta \beta P$. Assume with Murdock [33] that $\delta$ is a measure of the intensity of the agent's commitment to the public service. A high $\delta$ indicates that the agent is heavily engaged, while low $\delta$ indicates a low level of commitment to one's job. It is further assumed $\delta \geq 0$, which means that the public official is naturally motivated to be productive rather than destructive to the public service [34]. In other words, if his commitment to service is strong, he is less inclined to engage in a corruptive transaction.

The problem of the agent, thus posited, is reduced to a maximization of its utility:

$$
\max _{e_{p}, e_{c}}(1-q)(K+\delta \beta P+B)+q(1-\rho)(K+\delta \beta P)-C\left(e_{p}, e_{c}\right)
$$

Replacing $B, P$ and $C$ by their respective expression, the program of maximization of the agent becomes :

$$
\begin{aligned}
\max _{e_{p}, e_{c}} U= & \max _{e_{p}, e_{c}}(1-q)\left(K+\delta \beta\left(p e_{p}+\varepsilon\right)+b e_{c}\right) \\
& +q(1-\rho)\left[K+\delta \beta\left(p e_{p}+\varepsilon\right)\right]-\left(\frac{1}{2} e_{p}^{2}+\frac{1}{2} e_{c}^{2}+\gamma e_{p} e_{c}\right)
\end{aligned}
$$

The conditions of first order are:

$$
\begin{gathered}
\frac{\partial U}{\partial e_{c}}=b(1-q)-e_{c}-\gamma e_{p}=0 \\
\frac{\partial U}{\partial e_{p}}=\delta \beta p(1-q)-q \delta \beta p(1-\rho)-e_{p}-\gamma e_{c}=0
\end{gathered}
$$

From (1):

$$
\begin{gathered}
e_{c}=b(1-q)-\gamma e_{p} \\
e_{p}=\frac{1}{\gamma}\left[b(1-q)-e_{c}\right]
\end{gathered}
$$

From (2):

$$
\begin{gathered}
e_{c}=\frac{1}{\gamma}\left[\delta \beta p(1-q)-q \delta \beta p(1-\rho)-e_{p}\right] \\
e_{p}=\delta \beta p(1-q)-q \delta \beta p(1-\rho)-\gamma e_{c}
\end{gathered}
$$

Equalization of $\left(4^{\prime \prime}\right)=\left(5^{\prime \prime}\right)$ gives: 


$$
\begin{aligned}
e_{p}=e_{p} & \Rightarrow \delta \beta p(1-q)-q \delta \beta p(1-\rho)-\gamma e_{c}=\frac{1}{\gamma}\left[b(1-q)-e_{c}\right] \\
& \Rightarrow \gamma \delta \beta p(1-q)-q \delta \beta p(1-\rho)-\gamma^{2} e_{c}=b(1-q)-e_{c} \\
& \Rightarrow e_{c}\left(1-\gamma^{2}\right)=(1-q)(b-\gamma \delta \beta p)+\gamma q \delta \beta p(1-\rho) \\
& \Rightarrow e_{c}^{*}=\frac{1}{1-\gamma^{2}}[(1-q)(b-\gamma \delta \beta p)+\gamma q \delta \beta p]
\end{aligned}
$$

Equalization of $\left(4^{\prime}\right)=\left(5^{\prime}\right)$ gives: $e_{c}=e_{c}$

$$
\begin{aligned}
& \Rightarrow \frac{1}{\gamma}\left[\delta \beta p(1-q)-q \delta \beta p(1-\rho)-e_{p}\right]=b(1-q)-\gamma e_{p} \\
& \Rightarrow \delta \beta p(1-q)-q \delta \beta p(1-\rho)-e_{p}=\gamma b(1-q)-\gamma^{2} e_{p} \\
& \Rightarrow \delta \beta p(1-q)-q \delta \beta p(1-\rho)-\gamma b(1-q)=\left(1-\gamma^{2}\right) e_{p}
\end{aligned}
$$

From where:

$$
e_{p}^{*}=\frac{1}{1-\gamma^{2}}[(1-q)(\delta \beta p-\gamma b)-q \delta \beta p(1-\rho)]
$$

\subsection{Model Predictions}

The propositions derived from the model resolution have formulated on the basis of optimal values of corruptive effort $e_{c}^{*}$ and the performance effort of the public procurement $e_{p}^{*}$.

A first proposition highlights the effect of increased control (regulatory pressure) on corruption and the performance of the procurement (Proposition 1). Another set of propositions addresses the conditions under which motivation for performance (Proposition 2) and the effect of agent discretionary margin (Proposition 3) influence downward effort and effort performance up. A fourth proposition involves the effect of the intensity of motivation on the corruption effort and the improvement of performance. The last proposition focuses on the influence of the compliance level on corruption and performance in government procurement (Proposition 5).

Proposition 1: Control only detects big corruption. On the other hand, any control leads to a decrease in the performance effort, which is therefore detrimental to the efficiency of public procurement.

The expression of the optimal effort of corruption effort $e_{c}^{*}$ suggests that an increase in the probability that the agent is controlled or the number of control which it is exposed has an ambiguous effect on the corruption effort. Indeed, the sign of expression $\frac{\partial e_{c}}{\partial q}=\frac{1}{1-\gamma^{2}}[2 \gamma \delta \beta p-b]$ is depending $2 \gamma \delta \beta p-b$. Furthermore $\frac{\partial e_{c}}{\partial q}<0$ if $b>2 \gamma \delta \beta p$. The effect of increased control over the corrupt effort is not obvious. In fact, control only reduces the corruption effort when the marginal benefit of the corruption effort is significant. In other words, this can be interpreted as the fact that control only makes it possible to detect the great corruption in which the sums involved are important. On the other hand, 
the influence of the control on the effort to the performance is unequivocal. Indeed $\frac{\partial e_{p}}{\partial q}=\delta \beta p(\rho-2)<0$ under the assumptions about the parameters $\delta$, $\beta$ and $p$.

This suggests that focusing on the fight against corruption in public procurement may reduce the effort to bribe public officials only under certain restrictive conditions. On the other hand, it has an obvious perverse effect on the agent's performance effort. Clearly, control appears as a limitation of the discretion of the public official which results in a loss of productivity of the performance effort.

Proposition 2: High control reduces the performance of government procurement

The effect of motivation is measured by the partial derivatives of optimal efforts of corruption and performance $\frac{\partial e_{c}}{\partial \beta}=\frac{\gamma \delta p}{1-\gamma^{2}}(2 q-1)<0 \Rightarrow q<\frac{1}{2}$

Increased motivation for performance can have a positive effect on the fight against corruption. To do this, the probability of control must be less than 0.5 . This result confirms the perverse effect of control on the performance of the public service $\frac{\partial e_{p}}{\partial \beta}=\frac{\delta p}{1-\gamma^{2}}(\rho-q)>0$ si $\rho>q$.

Increasing the motivation for performance induces a high performance effort if the level of compliance achieved is strictly greater than the probability of control. In other words, the motivation of the agent causes him a high performance effort, if $\rho$ the level of compliance reached is strictly greater than the probability of detecting deviant behavior.

Proposition 3: Discretion has a positive on the performance effort only when the number of control is low

In the model, $p$ is a measure of the public official's discretion. Thus, an increase in the discretion of the agent reduces the effort devoted to corruption. Indeed, the partial derivative of the corruption effort with respect to discretion is negative $\left(\frac{\partial e_{c}}{\partial p}=\frac{1-q}{1-\gamma^{2}}(-\gamma \delta \beta)<0\right)$. On the other hand, there is a lack of evidence of the impact of increased discretion on the performance effort $\left(\frac{\partial e_{p}}{\partial p}=\frac{1}{1-\gamma^{2}} \delta \beta(1-q(2+\rho))\right)$. The effect of discretion is positive if and only if $q<\frac{1}{2+\rho}$. Or by assumption $0 \leq \rho \leq 1$. Therefore, $\rho=1$ satisfies the condition. In that case, $q<\frac{1}{3}$. This can be interpreted as follows. Increased discretion has the expected positive effect on the performance effort only when the number of monitoring is low. A high number of controls would act in contradiction with the discretion by not allowing it to express itself.

The third interesting effect that can be drawn from discretion is its effect 
crossed with that of motivation. Indeed $\frac{\partial e_{c}}{\partial p \partial \beta}=-\frac{\gamma \delta}{1-\gamma^{2}}<0$. This means that the more discretion an agent has, the more effective the motivation for performance is in reducing the corruption effort. The resulting lesson is that the managerial flexibility left to an agent can be more effective in reducing corruption than the direct control/monitoring measures usually applied.

Proposition 4: The buyer's commitment to public service has a positive effect on the performance of procurement contracts.

Engagement intensity measures the agent's level of satisfaction with their service and can be used to gauge their willingness to improve public service performance. It has been assumed that $\delta \geq 0$, reflecting the fact that the agent is strongly engaged by his service and will tend to be productive rather than destructive.

The effect of the intensity of commitment on the performance effort is given by $\frac{\partial e_{p}}{\partial \delta}=\frac{\beta p}{1-\gamma^{2}}(1+q(\rho-2))$. Therefore $\frac{\partial e_{p}}{\partial \delta}>0$ is like $1+q(\rho-2)>0$. If $q<\frac{1}{2-\rho}$ an increase in the degree of commitment to the service causes an increase in the performance effort.

The relationship between the level of commitment and the corruption effort is given by the partial derivative of the corruption effort in relation to the intensity parameter of the commitment $\frac{\partial e_{c}}{\partial \delta}=\frac{\gamma \beta p}{1-\gamma^{2}}(2 q-1)$. This expression is negative if and only if, given the assumptions about the different parameters, $q<\frac{1}{2}$.

Proposition 5: The level of compliance, otherwise the degree of compliance with the formal rules, has no effect on corruption.

The compliance gap with respect to rules and procedures is defined as $1-\rho$ with $\rho$ being the level of compliance. The model assumed that only the deviant deviation observed is penalized. As a result, it is expected that the level of compliance achieved will have a negative impact on the corruption effort and positive on performance. To do this, we use the partial derivatives of the two stress functions in relation to $\rho$.

The influence of deviation on the corruption effort is $\frac{\partial e_{c}}{\partial \rho}=0$. The level of compliance achieved by the agent has no influence on the corruption effort. In other words, the agent may or may not yield to corrupt behavior by strictly adhering to the rules and procedures for public procurement. This is the case for example when it automatically retains the price as the sole criterion for evaluating offers. This may lead him to reward an offer offering the lowest price because having the lowest quality. This type of decision is accompanied, in order to be profitable for the contracting parties to the corruptive transaction, of various strategies of renegotiations of the contract. 
However, the effect of compliance on the performance of the public procurement is positive $\left(\frac{\partial e_{p}}{\partial \rho}=\frac{q \delta \beta p}{1-\gamma^{2}}>0\right)$. This suggests that a high level of compliance always improves the procurement efficiency. Table 1 summaries the propositions.

Table 1. Summury of propositions.

\begin{tabular}{cccccc}
\hline & \multicolumn{5}{c}{ Parameter } \\
\hline $\begin{array}{c}\text { Control } \\
q \in[0,1]\end{array}$ & $\begin{array}{c}\text { Motivation for per } \\
\text { formance } \beta \in] 0,1]\end{array}$ & Discretion $p \in] 0,1]$ & $\begin{array}{c}\text { Commitment } \\
\text { intensity } \delta \in] 0,1]\end{array}$ & Conformity $\rho \in[0,1]$ \\
\hline Corruption & $\frac{1}{1-\gamma^{2}}[2 \gamma \delta \beta p-b]$ & $\frac{\gamma \delta p}{1-\gamma^{2}}(2 q-1)$ & $\frac{1-q}{1-\gamma^{2}}(-\gamma \delta \beta) \leq 0$ & $\frac{\gamma \delta p}{1-\gamma^{2}}(2 q-1)$ & 0 \\
Performance & $\delta \beta p(\rho-2)<0$ & $\frac{\delta p}{1-\gamma^{2}}(\rho-q)$ & $\frac{1}{1-\gamma^{2}} \delta \beta[1-q(2+\rho)]$ & $\frac{\beta p}{1-\gamma^{2}}[1+q(\rho-2)]$ & $\frac{q \delta \beta p}{1-\gamma^{2}} \geq 0$ \\
\hline
\end{tabular}

Source: Author.

\section{Limitations and Prospects}

The proposed model presents a certain number of limits which are as many tracks for future developments.

The model assumes that the agent is competent and that the act of non-compliance is corrupt. Because of this, the compliance gap has been equated with corruption. However, non-compliance can raise an incompetence of the agent or negligence which it derives no profit [35]. On the question, one of the theoretical works most quoted in the literature is [15]. These authors propose a distinction between active waste and passive waste to analyze the role of incompetence in the squandering of public resources, which distinguishes between opportunism (corruption) and honest incompetence [35].

In addition, we have assumed that performance is solely a function of the effort for the public service. Recent literature has nevertheless stressed that public procurement is a complex set of transactions [36] that require a set of skills in law but also in economic analysis and financial management [21]. In its report on integrity in public procurement, the OECD [4] highlights the lack and inadequacy of the competencies of public procurement officials. This observation argues for taking into account in the theoretical model of competence in order to discriminate between the conscious deviant behavior to take advantage of it and the deviant behavior resulting from a lack of technical abilities [37] [38].

As noted by [35], opportunistic and self-interested behavior is not the only factor determining a situation in which the agent is not acting in the best interests of the principal. This may be due to (honest) incompetence or lack of information about the principal's real needs. In his critique of opportunism, Williamson [38] argues that opportunism is not a behavior shared by the majority of individuals. An agent may well be naturally honest or become honest due to fear of supervision and sanction and fail to achieve the objectives assigned to him due to lack of technical skills. 
Another hypothesis has been made implicitly about the objectives of the agent. The performance has been reduced to a single element. What seems strong. Because of their instrumental use for socio-economic and environmental policy purposes, several objectives, sometimes conflicting, are sought in public procurement by several principals [39]. The objectives assigned to the agent may, therefore, be poorly defined and consequently the performance will be too poorly specified. It may be worthwhile to improve the model by including, in addition to the objective of corruption, separately, the public procurement objective of minimizing costs and the socio-economic policy objective that can drive rising costs.

The third limiting assumption assumes that the probability of sanction is equal to the probability of the agent being audited or controlled. The relaxation of this constraint would make it possible to consider that any control does not lead to the detection of deviant behaviors. Even better, it might be interesting to consider that all deviant behavior is not punished. This would lead to retaining a threshold of deviance to trigger sanctions.

In addition, the model considers the probability of control and sanction as exogenous. However, the penalty generally results from the observation of a deviant behavior or a red flag given by a third party (evicted bidders, investigative press, civil society organization, whistleblowers, etc.). This deviation can be the conduct of procurement procedure below the imposed standard or the production of an effort below that required or the achievement of a performance below the threshold. It might therefore be interesting to consider that control is a function of the corruption effort and the performance effort. However, it is possible to have some intuitions about the results of a model with a probability of endogenous control. By imagining that control aims at conforming behavior on the basis of index of non-conformity or non-performance, an increased effort for performance should negatively affect the occurrence of the audit and vice versa for the corruption effort.

Finally, the model did not explicitly include the fact that apart from the internal purchasing tasks delegated by the principal, the agent is engaged in some kind of external contracts with third parties (political opponents, bidders ousted, and interest groups). Neither the principal nor the agent are able to control orinfluence them. Even worse, the principal may find himself under the influence and control of those parties external to public procurement activities. These third parties as [2] present as opportunists are not necessarily interested in the success of the contractual relationship. In this case, the behavior of the agent is no longer solely shaped by the policy (evaluation, incentive, work design) of the primary principal, but also by the respective policies of the secondary principals external to the public purchase. This seems to be the situation prevailing in public procurement the influence of civil society, the media, political opponents and donors is omnipresent.

The inclusion of these opportunistic third parties leads to consider not a multitasking environment with a single principal but a multitasking framework with 
several principals. Such a framework would lead to consider two hypotheses about the moral hazard of the agent which is worth the control and the sanction. The first is as follows: the problem of moral hazard lies in the insufficiency of the total efforts made. The second posits that the problem of the hazard lies in the inefficient distribution of efforts between the various tasks (or objectives) or principal.

\section{Conclusions}

The aim of the paper was to analyze the effects of integrity concerns on corruption in public procurement and efficiency the procurement contracts. To do this, the article has considered regulatory and procedural pressure as well as surveillance and control as all mechanisms for controlling corruption and promoting procurement efficiency. Using the multi-tasking framework of agency theory developed by Holmstrom and Milgrom [23], the theoretical model highlights traditional instruments used to fight corruption (oversight and sanction) and to improve performance (incentives) in public procurement are not always effective. In particular, it shows that the monitoring intensity is likely to produce completely opposite effects to those intended namely to undermine civil servant's motivation to procurement performance and to corruption reduction.

The article draws the conclusion that although monitoring and control can have many advantages (less discretion leading to less corruption and more performance), the "race to regulatory compliance" can lead to some drift. The consequence is to forget what should be the main objective which is to improve the performance of the public procurement contracts. However, the problem does not seem to be specific to public procurement. In fact, as soon as any criterion, supposed to make it possible to answer a given problematic, takes a predominant place in a system, then the economic agent may tend to optimize his effort to satisfy this criterion while forgetting the problematic underlying. This does not mean, however, that the indicator is necessarily bad. This conclusion highlights the distortion of incentives in public procurement objectives and opens the way for an analysis of the effects of these distortions on the behavior of the public buyer.

\section{Conflicts of Interest}

The author declares no conflicts of interest regarding the publication of this paper.

\section{References}

[1] Rizzo, I. (2013) Efficiency and Integrity Issues in Public Procurement Performance. Journal of Public Finance and Public Choice, 31, 111-128.

[2] Moszoro, M.W. and Spiller, P.T. (2012) Three Isn't Always a Charm: Third-Party Opportunism, Scrutiny, and the (In)Efficiency of Public Contracts. Working Paper. https://doi.org/10.2139/ssrn.1969105

[3] D’Souza, A. and Kaufmann, D. (2013) Who Bribes in Public Contracting and Why: 
Worldwide Evidence from Firms. Economics of Governance, 14, 333-367. https://doi.org/10.1007/s10101-013-0130-5

[4] OCDE (2010) Principes de l'OCDE pour renforcer l'intégrité dans les marchés publics. OCDE, Paris.

[5] World Bank (2017) Benchmarking Public Procurement 2017. The World Bank, Washington DC.

[6] Chong, E., Staropoli, C. and Yvrande-Billon, A. (2013) Enchères ou négociations dans les marchés publics: Une analyse empirique. Revue déconomie industrielle, 1 , 51-72. https://doi.org/10.4000/rei.5512

[7] Williams-Elegbe, S. (2013) The World Bank's Influence on Procurement Reform in Africa. African Journal of International and Comparative Law, 21, 95-119. https://doi.org/10.3366/ajicl.2013.0053

[8] World Bank (2007) Corruption and Technology in Public Procurement.

[9] IMF (2005) Building Institutions.

[10] Coppier, R. and Piga, G. (2006) Why Do Transparent Public Procurement and Corruption Go Hand in Hand? Rivista di Politica Economica, 96, 185-206.

[11] Mwangangi, P. and Owuoth, G.G. (2015) Effect of Public Procurement Regulations on Procurement Performance in Public Sector in Kenya: A Case of Rural Electrification Authority. International Journal of Social Sciences Management and Entrepreneurship, 2, 171-184.

[12] Odhiambo, W. and Kamau, P. (2003) Public Procurement: Lessons from Kenya, Tanzania and Uganda. Working Paper, No. 1208.

[13] Williams-Elegbe, S. (2015) A Comparative Analysis of Public Procurement Reforms in Africa: Challenges and Prospects. Procurement Law Journal, 1, 11-32.

[14] Anechiarico, F. and Jacobs, J.B. (1996) The Pursuit of Absolute Integrity: How Corruption Control Makes Government Ineffective. University of Chicago Press, Chicago.

[15] Bandiera, O., Prat, A. and Valletti, T. (2009) Active and Passive Waste in Government Spending: Evidence from a Policy Experiment. American Economic Review, 99, 1278-1308. https://doi.org/10.1257/aer.99.4.1278

[16] Transparency International (2003) Global Report 2003-Special Focus: Access to Information. Profile Books Ltd., London.

[17] McCubbins, M.D., Noll, R.G. and Weingast, B.R. (1987) Administrative Procedures as Instruments of Political Control. Journal of Law, Economics, \& Organization, 3 , 243-277.

[18] Bolton, P. (2006) Government Procurement as a Policy Tool in South Africa. Journal of Public Procurement, 6, 193-217. https://doi.org/10.1108/JOPP-06-03-2006-B001

[19] OCDE (2015) L'utilisation stratégique des marchés publics. Chez Panorama des administrations publiques 2013. OCDE, Paris.

[20] Rogerson, C.M. (2004) Pro-Poor Local Economic Development in South Africa, the Application of Public Procurement. Urban Forum, 15, 180-210. https://doi.org/10.1007/s12132-004-0019-Z

[21] Saussier, S. and Tirole, J. (2015) Renforcer l'efficacité de la commande publique. Notes du conseil d'analyse économique, No. 122, 1-12. https://doi.org/10.3917/ncae.022.0001

[22] Dixit, A. (1987) Strategic Behavior in Contests. The American Economic Review, 


\section{7, 891-898.}

[23] Holmstrom, B. and Milgrom, P. (1991) Multitask Principal-Agent Analyses: Incentive Contracts, Asset Ownership, and Job Design. Journal of Law, Economics, \& Organization, 7, 24-52. https://doi.org/10.1093/jleo/7.special_issue.24

[24] Segal, L. (1997) The Pitfalls of Political Decentralization and Proposals for Reform: The Case of the New York City Schools. Public Administration Review, 57, 141-149. https://doi.org/10.2307/977062

[25] Klitgaard, R. (1988) Controlling Corruption. University of California Press, Berkeley.

[26] Rose-Ackerman, S. (1978) Corruption. A Study in Political Economy. Academic Press, New York. https://doi.org/10.1016/B978-0-12-596350-3.50005-3

[27] OCDE (2007) Corruption dans les marchés publics: Méthodes, acteurs et contremesures. Paris.

[28] Kwon, I. (2014) Motivation, Discretion, and Corruption. Journal of Public Administration Research and Theory, 24, 765-794. https://doi.org/10.1093/jopart/mus062

[29] Simon, H.A. (1951) A Formal Theory of the Employment Relationship. Econometrica, 19, 293-305. https://doi.org/10.2307/1906815

[30] Conseil d'Etat (2002) Collectivités publiques et concurrence. Paris.

[31] Rob, R. and Zemsky, P. (2002) Social Capital, Corporate Culture, and Incentive Intensity. RAND Journal of Economics, 33, 243-257. https://doi.org/10.2307/3087432

[32] Socorro, M.P. (2007) Optimal Technology Policy under Asymmetric Information in a Research Joint Venture. Journal of Economic Behavior \& Organization, 62, 76-97. https://doi.org/10.1016/j.jebo.2005.02.002

[33] Martimort, D. and Pouyet, J. (2008) To Build or Not to Build: Normative and Positive Theories of Public-Private Partnerships. International Journal of Industrial Organization, 26, 393-411. https://doi.org/10.1016/j.ijindorg.2006.10.004

[34] Murdock, K. (2002) Intrinsic Motivation and Optimal Incentive Contracts. The RAND Journal of Economics, 33, 650-671. https://doi.org/10.2307/3087479

[35] James Jr., H.S. (2005) Why Did You Do That? An Economic Examination of the Effect of Extrinsic Compensation on Intrinsic Motivation and Performance. Journal of Economic Psychology, 26, 549-566. https://doi.org/10.1016/j.joep.2004.11.002

[36] Kauppi, K. and van Raaij, E.M. (2014) Opportunism and Honest Incompetence-Seeking Explanations for Noncompliance in Public Procurement. Journal of Public Administration Research and Theory, 25, 953-979.

https://doi.org/10.1093/jopart/mut081

[37] Léon De Mariz, C., Ménard, C. and Abeillé, B. (2014) Public Procurement Reforms in Africa: Challenges in Institutions and Governance. Oxford University Press, Oxford. https://doi.org/10.1093/acprof:oso/9780198714910.001.0001

[38] Hendry, J. (2002) The Principal's Other Problems: Honest Incompetence and the Specification of Objectives. Academy of Management Review, 27, 98-113. https://doi.org/10.5465/amr.2002.5922406

[39] Williamson, O. (1993) Opportunism and Its Critics. Managerial and Decision Economics, 14, 97-107. https://doi.org/10.1002/mde.4090140203 